\title{
Role of $S$-adenosylmethionine cycle in carcinogenesis
}

\author{
Radovan Murín ${ }^{1}$, Eva Vidomanová2, Bhavani S. Kowtharapu ${ }^{3}$, Jozef Hatok ${ }^{1}$ and Dušan Dobrota ${ }^{1}$ \\ ${ }^{1}$ Department of Medical Biochemistry, Jessenius Faculty of Medicine in Martin, Comenius University in Bratislava, Martin, \\ Slovakia \\ ${ }^{2}$ Biomedical Center Martin, Jessenius Faculty of Medicine in Martin, Comenius University in Bratislava, Martin, Slovakia \\ ${ }^{3}$ Department of Ophthalmology, University of Rostock, Rostock, Germany
}

\begin{abstract}
Alterations in enzymatic activities underlying the cellular capacity to maintain functional S-adenosylmethionine (SAM) cycle are associated with modified levels of its constituents. Since SAM is the most prominent donor of methyl group for sustaining the methylation pattern of macromolecules by methyltransferases, its availability is an essential prerequisite for sustaining the methylation pattern of nucleic acids and proteins. In addition, increased intracellular concentrations of $S$-adenosylhomocysteine and homocysteine, another two constituents of SAM cycle, exerts an inhibitory effect on the enzymatic activity of methyltranferases. While methylation pattern of DNA and histones is considered as an important regulatory hallmark in epigenetically regulated gene expression, amended methylation of several cellular proteins, including transcription factors, affects their activity and stability. Indeed, varied DNA methylome is a common consequence of disturbed SAM cycle and is linked with molecular changes underlying the transformation of the cells that may underlay the carcinogenesis. Here we summarize the recent evidences about the impact of disturbed SAM cycle on carcinogenesis.
\end{abstract}

Key words: S-adenosylmethionine - DNA methylation - Cancer - Epigenetic regulationMetabolism

\section{Introduction}

The gain or subsequent loss of methyl group by macromolecules plays a significant regulatory role in cellular signal transduction with profound impact on modulation of physiological responses (Jaenisch and Bird 2003; Biggar and Li 2015) on all levels in organism. The methylation status of DNA and histones are considered important epigenetic hallmarks with profound impact on several processes including cellular differentiation, chromosomal organization and stability as well as epigenetically regulated gene expression (Jaenisch and Bird 2003). In addition to histones, also the methylation of several other proteins controls their enzymatic activity, feasibility for protein-protein interaction and stability (Biggar and Li 2015). Dysregulations in processes fundamental for generation, maintaining or removal of

Correspondence to: Radovan Murín, Department of Medical Biochemistry, Jessenius Faculty of Medicine in Martin, Comenius University in Bratislava, Malá hora 4D, 03601 Martin, Slovakia

E-mail: murin@jfmed.uniba.sk methyl moieties from macromolecules has been implicated in etiology of several diseases (Feinberg 2007), including cancer (Jones and Baylin 2002, 2007).

In human cells, along with $S$-adenosylmethionine (SAM) also structural analogues of tetrahydrofolate (THF) serve the roles of methyl-group donors. While, SAM is the most common donor of a methyl group for the substrate-specific methyltransferases, which facilitate the processes of DNA, RNA and protein methylation (Chiang et al. 1996), the structural analogues of THF are mostly involved in synthetic reactions of nucleotides and amino acids. Since, 5-methyl THF is a compound essential for re-synthesis of methionine from homocysteine by methionine synthase (Selhub 2002), it links metabolism of THF with SAM. The metabolism of SAM includes reactions of its synthesis and regeneration, which are arranged in a pathway known as SAM-cycle (Fig. 1). Sustaining of SAM-cycle is dependent on intermediary metabolism and can be negatively affected by a dietary supply of several essential nutrients, e.g., methionine, folate, cobalamin and pyridoxine. Impaired dietary supply, absorption, distribution, metabolism or enzymatic processing of 


\section{Polyamines}

\section{SPDSI
SPMS}

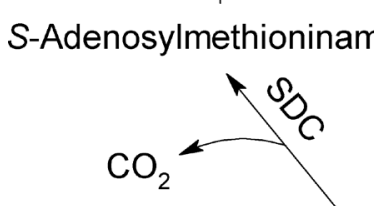

S-Adenosylmethionine

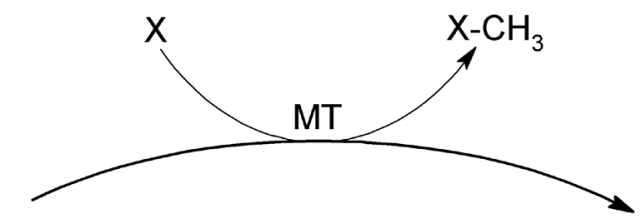

S-Adenosylhomocysteine

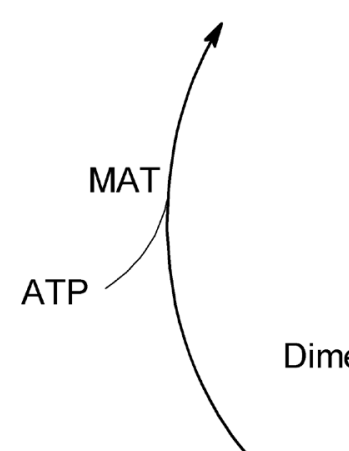<smiles>CCCCCCCC</smiles>

Diet

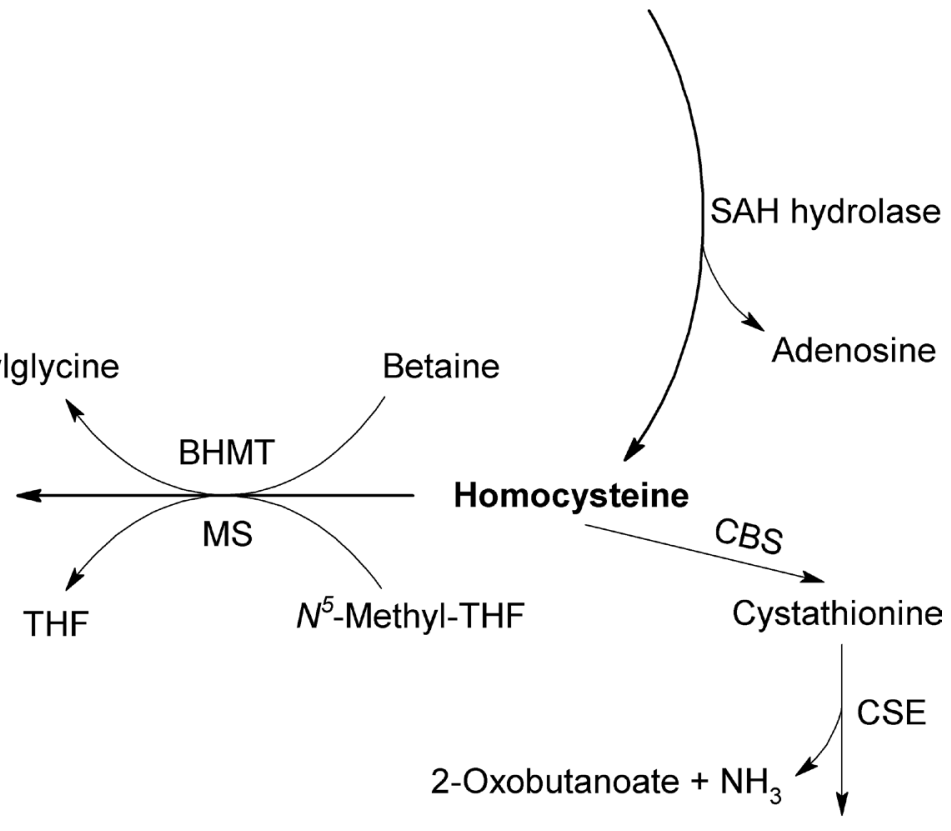

Cysteine

Figure 1. The scheme of the $S$-adenosylmethionine (SAM) cycle. Methionine adenosyltransferase (MAT) converts methionine and ATP to SAM, which subsequently may enter two distinct metabolic pathways. After decarboxylation of SAM to S-adenosylmethioninamine by SAM decarboxylase (SDC), it serves a role of aminopropyl group donor for polyamine synthesis enzymatically catalyzed by spermidine synthase (SPDS) and spermine synthase (SPMS). In trans-methylation reactions, catalyzed by methyltransferases (MT), SAM donates methyl group to variety of the substrates and is converted to $S$-adenosylhomocysteine (SAH) that is cleaved by SAH hydrolase to homocysteine and adenosine. Homocysteine is either remethylated to methionine or by transsulfuration reactions converted to 2-oxobutanoate and cysteine. The remethylation may be catalyzed by either of two enzymes, methionine synthase (MS) or betaine homocysteine methyltransferase (BHMT) those require as a source of methyl group either 5-methyl tetrahydrofolate ( $N^{5}$-Methyl-THF) or betaine, respectively. The transsulfuration pathway requires serine as second co-substrate for cystathionine $\beta$-synthase (CBS) to generate cystathionine that is subsequently hydrolyzed by cystathionine $\gamma$-lyase (CSE).

these nutrients negatively impacts the cellular level of SAM. Suppressed production of SAM is linked with amendments in methylation reactions of macromolecules. The changes in methylation pattern of macromolecules could increase the risk of cellular transformation leading to cancer (Jones and Baylin 2002, 2007).

Indeed, the results of several performed studies show that deficiency of folate, $\mathrm{B}_{12}$, or methionine are affecting serum and cellular levels of SAM, S-adenosylhomocysteine and homocysteine, and are linked with molecular processes contributing to oncogenesis (Lu and Mato 2012; Hirschey et al. 2015). Among others tissues, the liver is the most common and the best studied organ undergoing a cellular transformation to hepatocellular carcinoma due to disturbed capability to maintain physiological SAM level (Ramani et al. 2011; Lu and Mato 2012). Besides the nutritional composition of the diet and a capability of the organism to absorb, metabolize and distribute these essential components to particular tis- 
sues, the controlling mechanisms of enzymatic activity of the enzymes participating on the SAM metabolism should be taken into account.

\section{S-Adenosylmethionine metabolism}

The enzymatic reactions of formation, transmethylation and further regeneration of SAM are ordered in a cyclic metabolic pathway named SAM-cycle (Fig. 1), which is ubiquitously present across all tissues. The first reaction, the synthesis of SAM from methionine and ATP is catalyzed by methionine adenosyltransferase (MAT; EC 2.5.1.6), also known as SAM synthetase. In cellular metabolism, SAM possesses three distinct functions. SAM can be decarboxylated by SAM decarboxylase [EC 4.1.1.50] to $S$-adenosylmethioninamine, which is a donor of propylamine residue in polyamine synthetic pathway (Fig. 1). The second, the least studied role of SAM in human cells is to donate 5 '-deoxyadenosyl radical (Duschene and Broderick 2010). The most prominent metabolic function of SAM is its role of a methyl-group donor in variety reactions catalyzed by enzymes from a methyltransferase family (Fontecave et al. 2004). Indeed, more than $90 \%$ of formed SAM molecules are consumed for sustaining the methylation reactions and only up to $5 \%$ for the generation of $S$-adenosylmethioninamine. In humans, the liver is the organ with highest turnover of SAM and metabolism of methionine (Mato et al. 2002).

Methyltransferases generate $S$-adenosylhomocysteine, which is subsequently hydrolyzed to homocysteine and adenosine by $S$-adenosylhomocysteine hydrolase [EC 3.3.1.1]. This reversible reaction of $S$-adenosylhomocysteine hydrolysis is characterized by an equilibrium constant lower than one and therefore the reversible synthesis of $S$-adenosylhomocysteine is energetically favorable (Finkelstein 1990). The produced homocysteine is precursor for resynthesis of methionine or donate a sulfhydryl group to serine during cysteine anabolism in an order of two enzymatic reactions catalyzed by cystathionine $\beta$-synthase [4.2.1.22] and cystathionine $\gamma$-lyase [4.4.1.1]. The both enzymes, cystathionine $\beta$-synthase and cystathionine $\gamma$-lyase, are vitamin $\mathrm{B}_{6}$-dependent and among the products of their mutual activity belong cysteine, ammonia, 2-oxobutanoate (Fig. 1) and hydrogen sulfide (Yang et al. 2008; Szabo et al. 2013). Enzymatic conversion of homocysteine to cysteine significantly contributes to maintaining the cysteine level and subsequently also to synthesis of glutathione (Mosharov et al. 2000). Hydrogen sulfide is a gaseous signaling molecule with impact on several cellular (Li et al. 2011), physiological (Yang et al. 2008) and pathophysiological functions (Szabo et al. 2013; Sen et al. 2015). In colon cancer cells, hydrogen sulfide supports cellular bioenergetics, tumor growth and proliferation, as well as promotes angiogenesis and vasorelaxation
(Szabo et al. 2013), while hydrogen sulfide released from human breast cancer cells prevents the suppressive effect of activation macrophage on their growth (Sen et al. 2015).

The regeneration of methionine from homocysteine can be catalyzed by two distinct enzymes, either by cobalamin-dependent methionine synthase (Banerjee and Matthews 1990; [EC 2.1.1.13]) or $\mathrm{Zn}^{2+}$-dependent enzyme from thiolmethyltransferase family - betaine homocysteine methyltransferase (Pajares and Pérez-Sala 2006; [EC 2.1.1.5]), which utilize as a co-substrate either 5-methyl THF or betaine, respectively.

In contrast to SAM and $S$-adenosylhomocysteine, the remaining two members of SAM cycle - homocysteine (Tsitsiou et al. 2009) and methionine (Bröer 2008) - can be transported through the plasma membrane by specific transporters. Therefore, increased serum concentration of homocysteine might in addition to inherited genetic diseases also reflect either increased rate of SAM utilization followed by an insufficient regeneration of methionine from homocysteine, or suppressed conversion of homocysteine to cysteine.

\section{Effect of altered expression of MAT genes on carcinogenesis}

The early observations, that the inhibition of SAM production induced either by ethionine administration (Farber 1963) or methyl-deficient diet (Mikol et al. 1983; Ghoshal and Farber 1984) were followed by hepatocellular carcinoma, the studies focusing on the role of SAM metabolism in carcinogenesis have been initiated. Up today obtained results show that alterations in expression and activity of the enzymes involved in metabolism of SAM (Tab. 1) as well as the conditions associated with the deficiency or availability of essential nutrients, e.g., methionine, folic acid and cobalamin with negative impact on the cellular SAM levels are significant players in etiology in several cancer types (Tab. 1). Among them, the hepatocellular carcinoma is the most prominent cancer type (Lu and Mato 2012; Ramani et al. 2011), which has been most intensively studied.

The synthesis of SAM from methionine by MAT catalyzes reaction that is a rate limiting step in SAM cycle. In human tissues, three isoforms of MAT have been identified, which differ in their structure, tissue location, substrate specificity and kinetic parameters. The both isozymes, MAT I and III, are composed from catalytically active $\alpha 1$ subunits, which are assembled either in homotetrameric or homodimeric form, respectively. The switch between dimeric and tetrameric structures of MAT I/III isozymes impacts the total cellular activity of MAT (Cabrero et al. 1988; Markham and Pajares 2009 ) and is controlled by methionine availability (Sanchez del Pino et al. 2000). The al subunit is a product of MAT1A gene with predominant expression in adult liver. The isozyme MAT II consists from two distinct subunits, $\alpha 2$ and $\beta$, those 
may assembly together into the heterotetrameric structure. Two genes, MAT2A and MAT2B, are coding protein products $\alpha 2$ and $\beta$, respectively; those are widely expressed through the body. While a 2 subunit possesses the catalytic activity, the $\beta$ subunit exerts a regulatory effect on a catalytic activity of $\alpha 2$ subunit. The $\beta$ subunit lowers the both values of $\alpha 2$ subunit, $\mathrm{K}_{\mathrm{M}}$ for methionine and $\mathrm{K}_{\mathrm{i}}$ for SAM. Since SAM is a feedback inhibitor of only MAT II isoform, the expression and subsequent co-assembly of the $\alpha 2$ with $\beta$ subunit suppresses the synthesis of SAM and lower its cellular concentration (Martínez-Chantar et al. 2003a, 2003b).
In contrast to the expression of MAT1A gene, which predominates in adult liver, a gene product of MAT2A is predominantly expressed in all mammalian tissues and in fetal hepatocytes. Several studies show that the expression of all three genes, MAT1A, MAT2A and MAT2B, is changed in cells of multiple cancer types (Tab. 1). While the expression of MAT1A (Cai et al. 1996) is downregulated the levels of both, MAT2A (Cai et al. 1996; Liu et al. 2011; Tomasi et al. 2015; Yang et al. 2015) and MAT2B (Martínez-Chantar et al. 2003a), gene products are increased. This relates with isozyme switch of MAT I/III to MAT II that leads to lowering

Table 1. Alterations in expression of SAM cycle genes associated with carcinogenesis

\begin{tabular}{|c|c|c|c|c|}
\hline Gene & Change & Effect & Cancer type & References \\
\hline \multirow[t]{3}{*}{ MAT1A } & $\downarrow$ mRNA & $\downarrow$ Expression of MAT & Hepatocellular carcinoma & Cai et al. 1996 \\
\hline & Coding region methylation & $\downarrow$ Expression of MAT & Hepatocellular carcinoma & Tomasi et al. 2012 \\
\hline & $\downarrow$ Expression & $\downarrow$ Expression of MAT & Cholangiocarcinoma & Yang et al. 2016 \\
\hline \multirow[t]{7}{*}{ MAT2A } & 个 Enzyme sumoylation & $\begin{array}{l}\uparrow \text { Bcl-2 expression } \\
\text { Suppress apoptosis }\end{array}$ & $\begin{array}{l}\text { Colon cancer cells } \\
\text { Liver cancer cells }\end{array}$ & Tomasi et al. 2015 \\
\hline & $\downarrow$ Enzyme acetylation & $\uparrow$ Tumor cell growth & Hepatocellular carcinoma & Yang et al. 2015 \\
\hline & $\downarrow$ Expression & $\uparrow$ Tumor cell growth & Renal & Wang et al. 2014 \\
\hline & $\uparrow$ Expression & $\uparrow$ Tumor cell growth & Hepatoma cells & Liu et al. 2011 \\
\hline & $\uparrow$ Expression & $\uparrow$ Tumor cell growth & Gastric & Zhang et al. 2013 \\
\hline & $\uparrow \mathrm{mRNA}$ & $\uparrow$ Tumor cell growth & Colon & Chen et al. 2007 \\
\hline & $\uparrow$ Expression & $\uparrow$ Tumor cell growth & Leukemic T cells & Halim et al. 2001 \\
\hline \multirow[t]{3}{*}{$M A T 2 B$} & $\uparrow$ Expression & $\downarrow$ SAM & Hepatocellular carcinoma & Martínez-Chantar et al. 2003a \\
\hline & Interaction with GIT1 & Activation of ERK and MEK & $\begin{array}{l}\text { Hepatocellular carcinoma } \\
\text { Colon cancer }\end{array}$ & Peng et al. 2013 \\
\hline & & $\begin{array}{l}\text { Predicted modified methylation } \\
\text { status of DNA }\end{array}$ & Multiple types & Mehrmohamadi et al. 2016 \\
\hline \multirow[t]{2}{*}{ SAH hydrolase } & Mutations & $\downarrow$ Activity & $\begin{array}{l}\text { Kidney } \\
\text { Small intestine } \\
\text { Pancreas } \\
\text { Skin }\end{array}$ & Leal et al. 2008 \\
\hline & Mutations & $\downarrow$ Activity & Liver & Stender et al. 2015 \\
\hline \multirow[t]{2}{*}{ BHMT } & Mutation & $\downarrow$ Activity & Hepatocellular carcinoma & $\begin{array}{l}\text { Pellanda et al. } 2012 \\
\text { Pellanda } 2013\end{array}$ \\
\hline & $\downarrow$ Expression & $\begin{array}{l}\uparrow \text { Tumor size } \\
\uparrow \alpha \text {-fetoprotein } \\
\uparrow \text { Vascular invasion }\end{array}$ & Hepatocellular carcinoma & Jin et al. 2016 \\
\hline BHMT2 & & $\begin{array}{l}\text { Predicted modified methylation } \\
\text { status of DNA }\end{array}$ & Multiple types & Mehrmohamadi et al. 2016 \\
\hline \multirow[t]{4}{*}{ MTR } & A2756G polymorphismus & $\uparrow$ Risk & Retinoblastoma & Akbari et al. 2015 \\
\hline & A2756G polymorphismus & $\uparrow$ Risk & Lung & Shi et al. 2005 \\
\hline & A2756G polymorphismus & $\uparrow$ Risk & Colorectal & de Vogel et al. 2009 \\
\hline & A2756G polymorphismus & $\uparrow$ Risk & Gastric & Kim et al. 2016 \\
\hline \multirow[t]{3}{*}{$M T R R$} & A66G polymorphism & $\uparrow$ Risk & Multiple forms & Wang et al. 2017 \\
\hline & A66G polymorphism & $\uparrow$ Risk & Lung & Shi et al. 2005 \\
\hline & A66G polymorphism & $\uparrow$ Risk & Colorectal & de Vogel et al. 2009 \\
\hline
\end{tabular}

$M A T$, methionine adenosyltransferase; $S A H$, $S$-adenosylhomocysteine; $B H M T$, betaine homocysteine methyltransferase; $M T R$, methionine synthase; $M T R R$, methionine synthase reductase; MEK1, mitogen-activated protein kinase kinase; GIT1, G protein-coupled receptor kinase interacting ArfGAP 1; ERK, extracellular signal-regulated kinase. 
of SAM concentration (LeGros et al. 2001; Frau et al. 2013) with subsequent dysregulation in methylation of DNA (Frau et al. 2012; Tomasi et al. 2012) and histones with impact on the gene expression (Mentch et al. 2015). The results of the several studies about the effect of the increased MAT2A expression revealed that increased level of MAT II isozyme positively enhances the proliferation of cancer stem cells ( $\mathrm{Lu}$ and Mato 2012) and may potentiate a cancer development and progression (Halim et al. 2001; Chen et al. 2007). In addition, suppressed expression of MAT2A gene yielding to the absence of MAT II isoform induces cell cycle arrest and apoptosis as well as suppresses a cancer cell proliferation (Wang et al. 2008; Liu et al. 2011; Zhang et al. 2013). The transcriptional switch from MAT1A to MAT2A is believed to be a consequence of SAM level decrease with further capability to suppress the negatively influence the level of SAM (Lu and Mato 2012) and facilitates the cancer cell survival and proliferation.

The expression of MAT2A gene and its enzymatic activity are regulated at both transcriptional and post-transcriptional levels. The level of MAT2A mRNA in hepatocellular cancer cells could be enhanced by several trans-activating transcription factors such as: Sp1, c-Myb, NF- $\kappa B$, AP-1 (Yang et al. 2001, 2003) and HIF-1a (Liu et al. 2011). Moreover, the covalent modifications yielding to histone acetylation, promoter region methylation contribute in regulation of MAT2A gene transcription (Frau et al. 2012). On posttranscriptional level, the stability of MAT2A mRNA is regulated by RNA-binding protein HuR. HuR can exist in methylated or un-methylated form. While, the presence of methylated HuR protein is associated with destabilization of MAT2A mRNA and decreased expression of a 2 subunit of MAT II isoform, the un-methylated HuR exerts an opposite effect (Vázquez-Chantada et al. 2010).

Covalent, post-transcriptional modifications of proteins have been identified as an evolutionarily conserved way affecting their enzymatic activities (Zhao et al. 2010). Dysregulations in placing, maintaining or removal of covalent marks on proteins affect their stability and/or activity with profound impact on cellular metabolism and may lead to carcinogenesis (Lin et al. 2013). Since, a 2 subunit of MAT II in addition to its enzymatic role in process of SAM synthesis possesses also several signaling functions. Increased acetylation (Yang et al. 2015) or suppressed sumoylation (Tomasi et al. 2015) of $\alpha 2$ subunit exerts anti-proliferative effect on cancer cells. While an acetylation of $\alpha 2$ subunit promotes its ubiquitination and subsequent proteasomal degradation and represses the tumor growth (Yang et al. 2015), sumoylation of a2 subunit is linked with its increased stability and enhanced expression of $\mathrm{Bcl}-2$ protein leading to cancer cell survival and growth (Tomasi et al. 2015). The regulatory role of MAT $\alpha 2$ subunit on the expression could be mediated by its interaction with several transcription factors and capability to func- tion as a transcriptional co-repressor (Katoh et al. 2011; Kera et al. 2013; Tomasi et al. 2015). In colon and hepatic cancer cells, also the expression of $\beta$ subunit of MAT II positively correlates with their survival, due to a capability of $\beta$ subunit to assembly with GIT1 protein (G protein coupled receptor kinase interacting ArfGAP 1) to a complex that activates ERK and MEK signaling pathways those are subsequently promoting the cancer cell growth (Peng et al. 2013).

In addition to above mentioned molecular mechanisms affecting the cellular level of SAM mediated by altering the expression of MAT isoforms, the enzymatic activity of MAT I/III may be further regulated by free radicals (for review see: Corrales et al. 2002). The primary structure of MAT al protein contains conserve cysteine 121 residue of which reduces sulfhydryl group is essential for sustaining the enzymatic activity. Conversion of this free sulfhydryl group by any reaction with the thiol-reacting compounds or insufficient capacity to regenerate it by reduced glutathione inhibits the enzymatic activity of MAT I/III. Among the thiol-reacting compounds belongs also free oxygen and nitrogen radicals. Indeed, hydroxyl radical, hydrogen peroxide, nitric oxide and peroxynitrite (Sánchez-Góngora et al. 1997; Avila et al. 1998) are capable to block the synthesis of SAM in liver cells by inhibition of MAT activity (Pajares et al. 2013).

\section{Influence of essential nutrients on SAM levels and SAM-related carcinogenesis}

In addition to above mentioned changes in MAT expression and activity the concentration of SAM and the flux of metabolites through SAM-cycle can be affected by mutations and/or polymorphism of the genes coding for remaining enzymatic constituents of SAM-cycle, which are participating in etiology of several cancer types (Tab. 1).

Furthermore, the levels of several essential nutrients may directly affect the flow of metabolites through SAM-cycle and SAM level (Mikol et al. 1983; Ghoshal and Farber 1984; Mentch et al. 2015) with the impact on the epigenetic changes underlying the carcinogenesis (Mehrmohamadi et al. 2016). In addition to methionine, the dietary supply of folic acid, cobalamin and pyridoxal is the solely way for sustaining their levels in human cells. The inadequate levels of those three $B$ vitamins are linked to several diseases including cancer (Poirier et al. 2001; Selhub 2002).

\section{Conclusion}

The processes, those compromise the cellular capacity to maintain the physiological level of SAM and SAM to $S$-adenosylhomocysteine ratio, are associated with disturbed methylation of biologically important molecules and undeni- 
ably are involved in etiology of several diseases. Since, altered methylation of DNA is recognized sign of cancer cells, alterations in rates of SAM cycle reactions with the impact on SAM level are considered to be significant players for a neoplastic transformation and cancer progression. Besides the genetic factors, which are affecting the metabolic operation of SAM cycle, the sufficient supply of the cells by several essential nutrients should be taken into account. Any deficiency of methionine, folic acid, $\mathrm{B}_{6}$ and $\mathrm{B}_{12}$ vitamins impairs the SAM cycle and increase the risk of spontaneous tumorigenesis. In this respect, it could be supposed that SAM cycle might possess the functions of i) a checking point for balanced nutritional status and ii) an executional point in transforming the "life style" to molecular epigenetic signals. Therefore, better understanding of the processes, which are either crucial for a sustaining the appropriately operating SAM cycle or may intervene with them, might be beneficial in prediction, prevention and therapeutic approaches for several cancer types.

Acknowledgment. This work was supported by the Slovak Research and Development Agency under the contract No. APVV0224-12. And in addition, this publication is the result of the project implementation: "Creating a new diagnostic algorithm for selected cancer diseases", ITMS code 26220220022 supported by the Operational Programme Research and Innovation funded by the ERDF. BSK was supported by Deutsche Forschungsgemeinschaft (DFG) (KO-4979/1-1).

\section{References}

Akbari M. T., Naderi A., Saremi L., Sayad A., Irani S., Ahani A. (2015): Methionine synthase A2756G variation is associated with the risk of retinoblastoma in Iranian children. Cancer Epidemiol. 39, 1023-1025 https://doi.org/10.1016/j.canep.2015.11.002

Avila M. A., Corrales F. J., Ruiz F., Sánchez-Góngora E., Mingorance J., Carretero M. V., Mato I. M. (1998): Specific interaction of methionine adenosyltransferase with free radicals. Biofactors 8, 27-32 https://doi.org/10.1002/biof.5520080106

Banerjee R. V., Matthews R. G. (1990): Cobalamin-dependent methionine synthase. FASEB J. 4, 1450-1459

Biggar K. K., Li S. S. (2015): Non-histone protein methylation as a regulator of cellular signalling and function. Nat. Rev. Mol. Cell. Biol. 16, 5-17 https://doi.org/10.1038/nrm3915

Bröer S. (2008): Amino acid transport across mammalian intestinal and renal epithelia. Physiol. Rev. 88, 249-286 https://doi.org/10.1152/physrev.00018.2006

Cabrero C., Duce A. M., Ortiz P., Alemany S., Mato J. M. (1988) Specific loss of the high-molecular-weight form of S-adenosylL-methionine synthetase in human liver cirrhosis. Hepatology 8, 1530-1534 https://doi.org/10.1002/hep.1840080610

Cai J., Sun W. M., Hwang J. J., Stain S. C., Lu S. C. (1996): Changes in Sadenosylmethionine synthetase in human liver cancer: molecular characterization and significance. Hepatology 24, 1090-1097 https://doi.org/10.1002/hep.510240519

Chen H., Xia M., Lin M., Yang H., Kuhlenkamp J., Li T., Sodir N. M., Chen Y. H., Josef-Lenz H., Laird P. W. et al. (2007): Role of methionine adenosyltransferase $2 \mathrm{~A}$ and $\mathrm{S}$-adenosylmethionine in mitogen-induced growth of human colon cancer cells. Gastroenterology 133, 207-218

https://doi.org/10.1053/j.gastro.2007.03.114

Chiang P. K., Gordon R. K., Tal J., Zeng G. C., Doctor B. P., Pardhasaradhi K., McCann P. P. (1996): S-Adenosylmethionine and methylation. FASEB J. 10, 471-480

Corrales F. J., Pérez-Mato I., Sánchez Del Pino M. M., Ruiz F., Castro C., García-Trevijano E. R., Latasa U., Martínez-Chantar M. L., Martínez-Cruz A., Avila M. A., Mato J. M. (2002): Regulation of mammalian liver methionine adenosyltransferase. J. Nutr. 132, 2377S-2381S

de Vogel S., Wouters K. A., Gottschalk R. W., van Schooten F. J., de Goeij A. F., de Bruïne A. P., Goldbohm R. A., van den Brandt P. A., Weijenberg M. P., van Engeland M. (2009): Genetic variants of methyl metabolizing enzymes and epigenetic regulators: associations with promoter $\mathrm{CpG}$ island hypermethylation in colorectal cancer. Cancer Epidemiol. Biomarkers Prev. 18, 3086-3096 https://doi.org/10.1158/1055-9965.EPI-09-0289

Duschene K. S., Broderick J. B. (2010): The antiviral protein viperin is a radical SAM enzyme. FEBS Lett. 584, 1263-1267 https://doi.org/10.1016/j.febslet.2010.02.041

Farber E. (1963): Ethionine carcinogenesis. Adv. Cancer Res. 7, $383-474$ https://doi.org/10.1016/S0065-230X(08)60986-0

Feinberg A. P. (2007): Phenotypic plasticity and the epigenetics of human disease. Nature 447, 433-440 https://doi.org/10.1038/nature05919

Finkelstein J. D. (1990): Methionine metabolism in mammals. J. Nutr. Biochem. 1, 228-237 https://doi.org/10.1016/0955-2863(90)90070-2

Fontecave M., Atta M., Mulliez E. (2004): S-adenosylmethionine: nothing goes to waste. Trends Biochem. Sci. 29, 243-249 https://doi.org/10.1016/j.tibs.2004.03.007

Frau M., Tomasi M. L., Simile M. M., Demartis M. I., Salis F., Latte G., Calvisi D. F., Seddaiu M. A., Daino L., Feo C. F. et al. (2012): Role of transcriptional and posttranscriptional regulation of methionine adenosyltransferases in liver cancer progression. Hepatology 56, 165-175 https://doi.org/10.1002/hep.25643

Frau M., Feo F., Pascale R. M. (2013): Pleiotropic effects of methionine adenosyltransferases deregulation as determinants of liver cancer progression and prognosis. J. Hepatol. 59, 830-841 https://doi.org/10.1016/j.jhep.2013.04.031

Ghoshal A. K., Farber E. (1984): The induction of liver cancer by dietary deficiency of choline and methionine without added carcinogens. Carcinogenesis 5, 1367-1370 https://doi.org/10.1093/carcin/5.10.1367

Halim A. B., LeGros L., Chamberlin M. E., Geller A., Kotb M. (2001): Regulation of the human MAT2A gene encoding the catalytic alpha 2 subunit of methionine adenosyltransferase, MAT II: gene organization, promoter characterization, and identification of a site in the proximal promoter that is essential for its activity. J. Biol. Chem. 276, 9784-9791 https://doi.org/10.1074/jbc.M002347200 
Hirschey M. D., DeBerardinis R. J., Diehl A. M., Drew J. E., Frezza C., Green M. F., Jones L. W., Ko Y. H., Le A., Lea M. A. et al. (2015): Dysregulated metabolism contributes to oncogenesis. Semin. Cancer Biol. 35, S129-S150 https://doi.org/10.1016/j.semcancer.2015.10.002

Jaenisch R., Bird A. (2003): Epigenetic regulation of gene expression: how the genome integrates intrinsic and environmental signals. Nat. Genet. 33, 245-254 https://doi.org/10.1038/ng1089

Jin B., Gong Z., Yang N., Huang Z., Zeng S., Chen H., Hu S., Pan G. (2016): Downregulation of betaine homocysteine methyltransferase (BHMT) in hepatocellular carcinoma associates with poor prognosis. Tumour Biol. 37, 5911-5917 https://doi.org/10.1007/s13277-015-4443-6

Jones P. A., Baylin S. B. (2002): The fundamental role of epigenetic events in cancer. Nat. Rev. Genet. 3, 415-428

Jones P. A., Baylin S. B. (2007): The epigenomics of cancer. Cell $128,683-692$ https://doi.org/10.1016/j.cell.2007.01.029

Katoh Y., Ikura T., Hoshikawa Y., Tashiro S., Ito T., Ohta M., Kera Y., Noda T., Igarashi K. (2011): Methionine adenosyltransferase II serves as a transcriptional corepressor of Maf oncoprotein. Mol. Cell. 41, 554-566 https://doi.org/10.1016/j.molcel.2011.02.018

Kera Y., Katoh Y., Ohta M., Matsumoto M., Takano-Yamamoto T., Igarashi K. (2013): Methionine adenosyltransferase IIdependent histone $\mathrm{H} 3 \mathrm{~K} 9$ methylation at the COX-2 gene locus. J. Biol. Chem. 288, 13592-13601 https://doi.org/10.1074/jbc.M112.429738

Kim W., Woo H. D., Lee J., Choi I. J., Kim Y. W., Sung J., Kim J. (2016): Dietary folate, one-carbon metabolism-related genes, and gastric cancer risk in Korea. Mol. Nutr. Food Res. 60, 337-345 https://doi.org/10.1002/mnfr.201500384

Leal J. F., Ferrer I., Blanco-Aparicio C., Hernández-Losa J., Ramón Y Cajal S., Carnero A., Lleonart M. E. (2008): S-adenosylhomocysteine hydrolase downregulation contributes to tumorigenesis. Carcinogenesis 29, 2089-2095 https://doi.org/10.1093/carcin/bgn198

LeGros L., Halim A. B., Chamberlin M. E., Geller A., Kotb M. (2001): Regulation of the human MAT2B gene encoding the regulatory beta subunit of methionine adenosyltransferase, MAT II. J. Biol. Chem. 276, 24918-24924 https://doi.org/10.1074/jbc.M102816200

Li L., Rose P., Moore P. K. (2011): Hydrogen sulfide and cell signaling. Annu. Rev. Pharmacol. Toxicol. 51, 169-187 https://doi.org/10.1146/annurev-pharmtox-010510-100505

Lin R., Tao R., Gao X., Li T., Zhou X., Guan K. L., Xiong Y., Lei Q. Y. (2013): Acetylation stabilizes ATP-citrate lyase to promote lipid biosynthesis and tumor growth. Mol. Cell. 51, 506-518 https://doi.org/10.1016/j.molcel.2013.07.002

Liu Q., Liu L., Zhao Y., Zhang J., Wang D., Chen J., He Y., Wu J., Zhang Z., Liu Z. (2011): Hypoxia induces genomic DNA demethylation through the activation of HIF-1alpha and transcriptional upregulation of MAT2A in hepatoma cells. Mol. Cancer Ther. 10, 1113-1123 https://doi.org/10.1158/1535-7163.MCT-10-1010

Lu S. C., Mato J. M. (2012): S-adenosylmethionine in liver health, injury, and cancer. Physiol. Rev. 92, 1515-1542 https://doi.org/10.1152/physrev.00047.2011

Markham G. D., Pajares M. A. (2009): Structure-function relationships in methionine adenosyltransferases. Cell. Mol. Life Sci. 66, 636-648 https://doi.org/10.1007/s00018-008-8516-1

Martínez-Chantar M. L., García-Trevijano E. R., Latasa M. U., Martín-Duce A., Fortes P., Caballería J., Avila M. A., Mato J. M. (2003a): Methionine adenosyltransferase II beta subunit gene expression provides a proliferative advantage in human hepatoma. Gastroenterology 124, 940-948 https://doi.org/10.1053/gast.2003.50151

Martínez-Chantar M. L., Latasa M. U., Varela-Rey M., Lu S. C., García-Trevijano E. R., Mato J. M., Avila M. A. (2003b): Lmethionine availability regulates expression of the methionine adenosyltransferase 2A gene in human hepatocarcinoma cells: role of S-adenosylmethionine. J. Biol. Chem. 278, 19885-19890 https://doi.org/10.1074/jbc.M211554200

Mato J. M., Corrales F. J., Lu S. C., Avila M. A. (2002): S-Adenosylmethionine: a control switch that regulates liver function. FASEB J. 16, 15-26 https://doi.org/10.1096/fi.01-0401rev

Mehrmohamadi M., Mentch L. K., Clark A. G., Locasale J. W. (2016): Integrative modelling of tumour DNA methylation quantifies the contribution of metabolism. Nat. Commun. 7, 13666 https://doi.org/10.1038/ncomms13666

Mentch S. J., Mehrmohamadi M., Huang L., Liu X., Gupta D., Mattocks D., Gómez Padilla P., Ables G., Bamman M. M., Thalacker-Mercer A. E. et al. (2015): Histone methylation dynamics and gene regulation occur through the sensing of one-carbon metabolism. Cell. Metab. 22, 861-873 https://doi.org/10.1016/j.cmet.2015.08.024

Mikol Y. B., Hoover K. L., Creasia D., Poirier L. A. (1983): Hepatocarcinogenesis in rats fed methyl-deficient, amino acid-defined diets. Carcinogenesis 4, 1619-1629

https://doi.org/10.1093/carcin/4.12.1619

Mosharov E., Cranford M. R., Banerjee R. (2000): The quantitatively important relationship between homocysteine metabolism and glutathione synthesis by the transsulfuration pathway and its regulation by redox changes. Biochemistry. 39, 13005-13011 https://doi.org/10.1021/bi001088w

Pajares M. A., Pérez-Sala D. (2006): Betaine homocysteine S-methyltransferase: just a regulator of homocysteine metabolism? Cell. Mol. Life Sci. 63, 2792-2803

https://doi.org/10.1007/s00018-006-6249-6

Pajares M. A., Alvarez L., Pérez-Sala D. (2013): How are mammalian methionine adenosyltransferases regulated in the liver? A focus on redox stress. FEBS Lett. 587, 1711-1716 https://doi.org/10.1016/j.febslet.2013.04.034

Pellanda H., Namour F., Fofou-Caillierez M., Bressenot A., Alberto J. M., Chéry C., Ayav A., Bronowicki J. P., Guéant J. L., Forges T. (2012): A splicing variant leads to complete loss of function of betaine-homocysteine methyltransferase (BHMT) gene in hepatocellular carcinoma. Int. J. Biochem. Cell. Biol. 44, 385-392 https://doi.org/10.1016/j.biocel.2011.11.014

Pellanda H. (2013): Betaine homocysteine methyltransferase (BHMT)-dependent remethylation pathway in human healthy and tumoral liver. Clin. Chem. Lab. Med. 51, 617-621 https://doi.org/10.1515/cclm-2012-0689 
Peng H., Dara L., Li T. W., Zheng Y., Yang H., Tomasi M. L., Tomasi I., Giordano P., Mato J. M., Lu S. C. (2013): MAT2B-GIT1 interplay activates MEK1/ERK 1 and 2 to induce growth in human liver and colon cancer. Hepatology 57, 2299-2313 https://doi.org/10.1002/hep.26258

Poirier L. A., Wise C. K., Delongchamp R. R., Sinha R. (2001): Blood determinations of S-adenosylmethionine, S-adenosylhomocysteine, and homocysteine: correlations with diet. Cancer Epidemiol. Biomarkers Prev. 10, 649-655

Ramani K., Mato J. M., Lu S. C. (2011): Role of methionine adenosyltransferase genes in hepatocarcinogenesis. Cancers 3, 1480-1497 https://doi.org/10.3390/cancers3021480

Sanchez del Pino M. M., Corrales F. J., Mato, J. M. (2000): Hysteretic behavior of methionine adenosyltransferase III. Methionine switches between two conformations of the enzyme with different specific activity. J. Biol. Chem. 275, 23476-23482 https://doi.org/10.1074/jbc.M002730200

Sánchez-Góngora E., Ruiz F., Mingorance J., An W., Corrales F. J., Mato J. M. (1997): Interaction of liver methionine adenosyltransferase with hydroxyl radical. FASEB J. 11, 1013-1019

Selhub J. (2002): Folate, vitamin B12 and vitamin B6 and one carbon metabolism. J. Nutr. Health Aging 6, 39-42

Sen S., Kawahara B., Gupta D., Tsai R., Khachatryan M., RoyChowdhuri S., Bose S., Yoon A., Faull K., Farias-Eisner R., Chaudhuri G. (2015): Role of cystathionine $\beta$-synthase in human breast cancer. Free Radic. Biol. Med. 86, 228-238 https://doi.org/10.1016/j.freeradbiomed.2015.05.024

Shi Q., Zhang Z., Li G., Pillow P. C., Hernandez L. M., Spitz M. R., Wei Q. (2005): Polymorphisms of methionine synthase and methionine synthase reductase and risk of lung cancer: a case-control analysis. Pharmacogenet. Genomics 15, 547-555 https://doi.org/10.1097/01.fpc.0000170916.96650.70

Stender S., Chakrabarti R. S., Xing C., Gotway G., Cohen J. C., Hobbs H. H. (2015): Adult-onset liver disease and hepatocellular carcinoma in S-adenosylhomocysteine hydrolase deficiency. Mol. Genet. Metab. 116, 269-274 https://doi.org/10.1016/j.ymgme.2015.10.009

Szabo C., Coletta C., Chao C., Módis K., Szczesny B., Papapetropoulos A., Hellmich M. R. (2013): Tumor-derived hydrogen sulfide, produced by cystathionine- $\beta$-synthase, stimulates bioenergetics, cell proliferation, and angiogenesis in colon cancer. Proc. Natl. Acad. Sci. USA 110, 12474-12479 https://doi.org/10.1073/pnas.1306241110

Tsitsiou E., Sibley C. P., D‘Souza S. W., Catanescu O., Jacobsen D. W., Glazier J. D. (2009): Homocysteine transport by systems L, $A$ and $y+L$ across the microvillous plasma membrane of human placenta. J. Physiol. 587, 4001-4013 https://doi.org/10.1113/jphysiol.2009.173393

Tomasi M. L., Li T. W., Li M., Mato J. M., Lu S. C. (2012): Inhibition of human methionine adenosyltransferase $1 \mathrm{~A}$ transcription by coding region methylation. J. Cell. Physiol. 227, 1583-1591 https://doi.org/10.1002/jcp.22875

Tomasi M. L., Ryoo M., Ramani K., Tomasi I., Giordano P., Mato J. M., Lu S. C. (2015): Methionine adenosyltransferase a2 sumoylation positively regulate $\mathrm{Bcl}-2$ expression in human colon and liver cancer cells. Oncotarget 6, 37706-37723

https://doi.org/10.18632/oncotarget.5342
Vázquez-Chantada M., Fernández-Ramos D., Embade N., MartínezLopez N., Varela-Rey M., Woodhoo A., Luka Z., Wagner C., Anglim P. P., Finnell R. H. et al. (2010): HuR/methyl-HuR and AUF1 regulate the MAT expressed during liver proliferation, differentiation, and carcinogenesis. Gastroenterology 138, 1943-1953 https://doi.org/10.1053/j.gastro.2010.01.032

Wang J. X., Lee E. R., Morales D. R., Lim J., Breaker R. R. (2008): Riboswitches that sense S-adenosylhomocysteine and activate genes involved in coenzyme recycling. Mol. Cell. 29, 691-702 https://doi.org/10.1016/j.molcel.2008.01.012

Wang X., Guo X., Yu W., Li C., Gui Y., Cai Z. (2014): Expression of methionine adenosyltransferase $2 \mathrm{~A}$ in renal cell carcinomas and potential mechanism for kidney carcinogenesis. BMC Cancer 14, 196 https://doi.org/10.1186/1471-2407-14-196

Wang P., Li S., Wang M., He J., Xi S. (2017): Association of MTRR A66G polymorphism with cancer susceptibility: Evidence from 85 studies. J. Cancer 8, 266-277 https://doi.org/10.7150/jca.17379

Yang H., Huang Z. Z., Wang J., Lu S. C. (2001): The role of c-Myb and $\mathrm{Sp} 1$ in the up-regulation of methionine adenosyltransferase $2 \mathrm{~A}$ gene expression in human hepatocellular carcinoma. FASEB J. 15, 1507-1516 https://doi.org/10.1096/fj.01-0040com

Yang H., Sadda M. R., Yu V., Zeng Y., Lee T. D., Ou X., Chen L., Lu S. C. (2003) Induction of human methionine adenosyltransferase 2A expression by tumor necrosis factor alpha. Role of NF-kappa B and AP-1. J. Biol. Chem. 278, 50887-50896 https://doi.org/10.1074/jbc.M307600200

Yang G., Wu L., Jiang B., Yang W., Qi J., Cao K., Meng Q., Mustafa A. K., Mu W., Zhang S., Snyder S. H., Wang R. (2008): H2S as a physiologic vasorelaxant: hypertension in mice with deletion of cystathionine gamma-lyase. Science 322, 587-590 https://doi.org/10.1126/science.1162667

Yang H. B., Xu Y. Y., Zhao X. N., Zou S. W., Zhang Y., Zhang M., Li J. T., Ren F., Wang L. Y., Lei Q. Y. (2015): Acetylation of MAT IIa represses tumour cell growth and is decreased in human hepatocellular cancer. Nat. Commun. 6, 6973 https://doi.org/10.1038/ncomms7973

Yang H., Liu T., Wang J., Li T. W., Fan W., Peng H., Krishnan A., Gores G. J., Mato J. M., Lu S. C. (2016): Deregulated methionine adenosyltransferase $\alpha 1, \mathrm{c}-\mathrm{Myc}$, and Maf proteins together promote cholangiocarcinoma growth in mice and humans. Hepatology 64, 439-455 https://doi.org/10.1002/hep.28541

Zhao S., Xu W., Jiang W., Yu W., Lin Y., Zhang T., Yao J., Zhou L., Zeng Y., Li H. et al. (2010): Regulation of cellular metabolism by protein lysine acetylation. Science 327, 1000-1004 https://doi.org/10.1126/science.1179689

Zhang T., Zheng Z., Liu Y., Zhang J., Zhao Y., Liu Y., Zhu H., Zhao G., Liang J., Li Q., Xu H. (2013): Overexpression of methionine adenosyltransferase II alpha (MAT2A) in gastric cancer and induction of cell cycle arrest and apoptosis in SGC-7901 cells by shRNAmediated silencing of MAT2A gene. Acta Histochem. 115, 48-55 https://doi.org/10.1016/j.acthis.2012.03.006

Received: April 21, 2017

Final version accepted: July 18, 2017 